\title{
Pendule, para trio de flauta, violoncelo e piano
}

\author{
Patricia De Carli \\ patriciadecarli87@gmail.com
}

\section{Comentário sobre a obra}

Pendule para trio é uma peça em que se busca traduzir por meios musicais o experimento do pêndulo de Léon Foucault (1819-1868). Quando o pêndulo é colocado em movimento, sua oscilação depende somente da força gravitacional, da tração e da resistência do ar, o que faz diminuir a amplitude das oscilações com o passar do tempo. Ao transpormos isto para a música, podemos considerar um eixo estrutural da peça a partir do qual alterações podem ou não ocorrer dependendo do ambiente que as entorna. Os materiais musicais contidos são interpretados como impulso, suspensão, relaxamento, aceleração e eixo. Quando os impulsos são aplicados ao pêndulo, as oscilações nunca são as mesmas pois as diferentes forças atuam sempre de forma diversa. $\mathrm{Na}$ forma musical isso é apresentado, por exemplo, na orquestração, como diferentes maneiras de mesclar o timbre, resultando em diferentes interpretações dos movimentos do pêndulo. Cada parte desta peça representa uma variação do ponto de vista dos aspectos físicos presentes em um pêndulo. 


\title{
PENDULE
}

\author{
pour flûte, violoncelle et piano
}

Très lent, calme $(\bullet=50)$
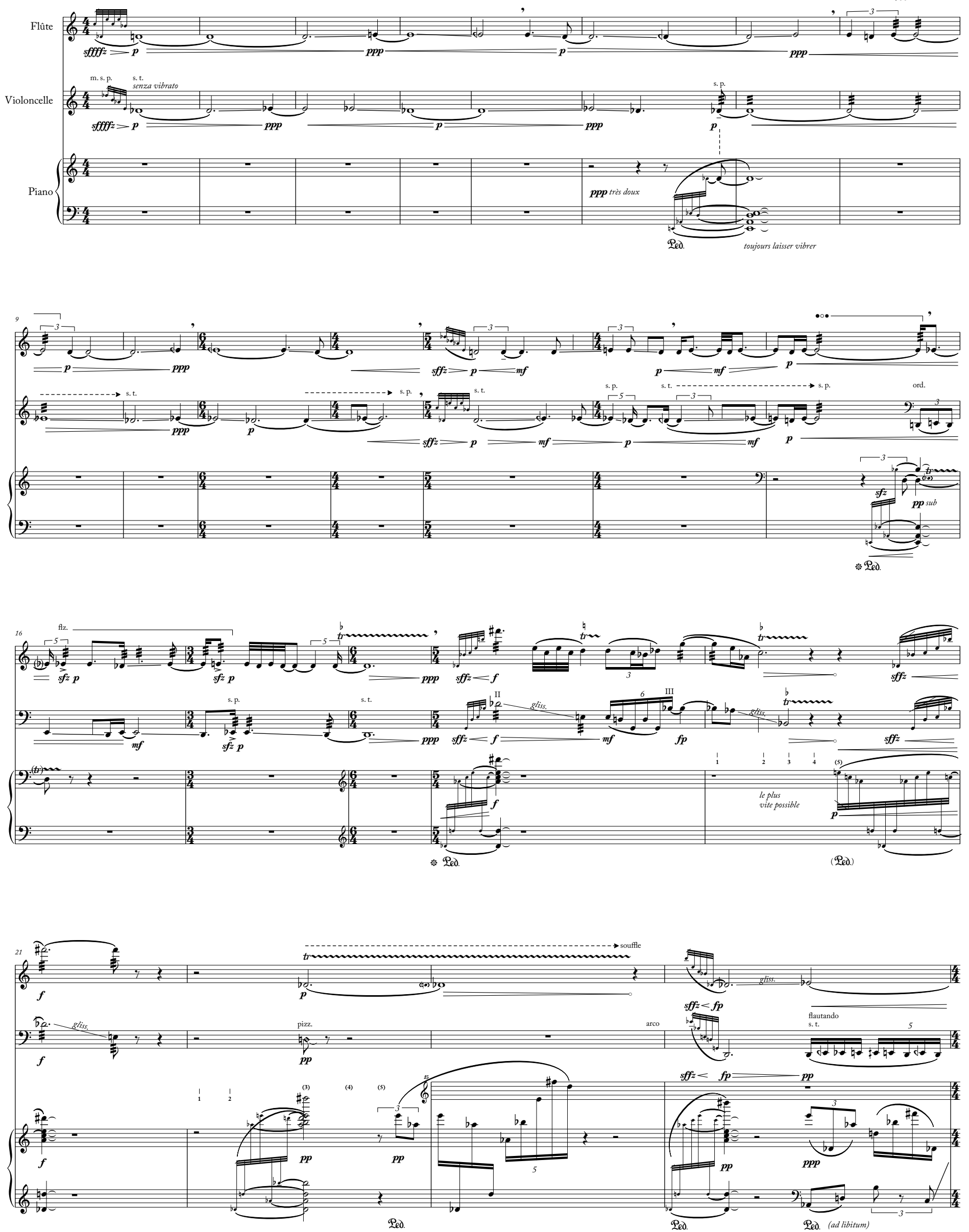


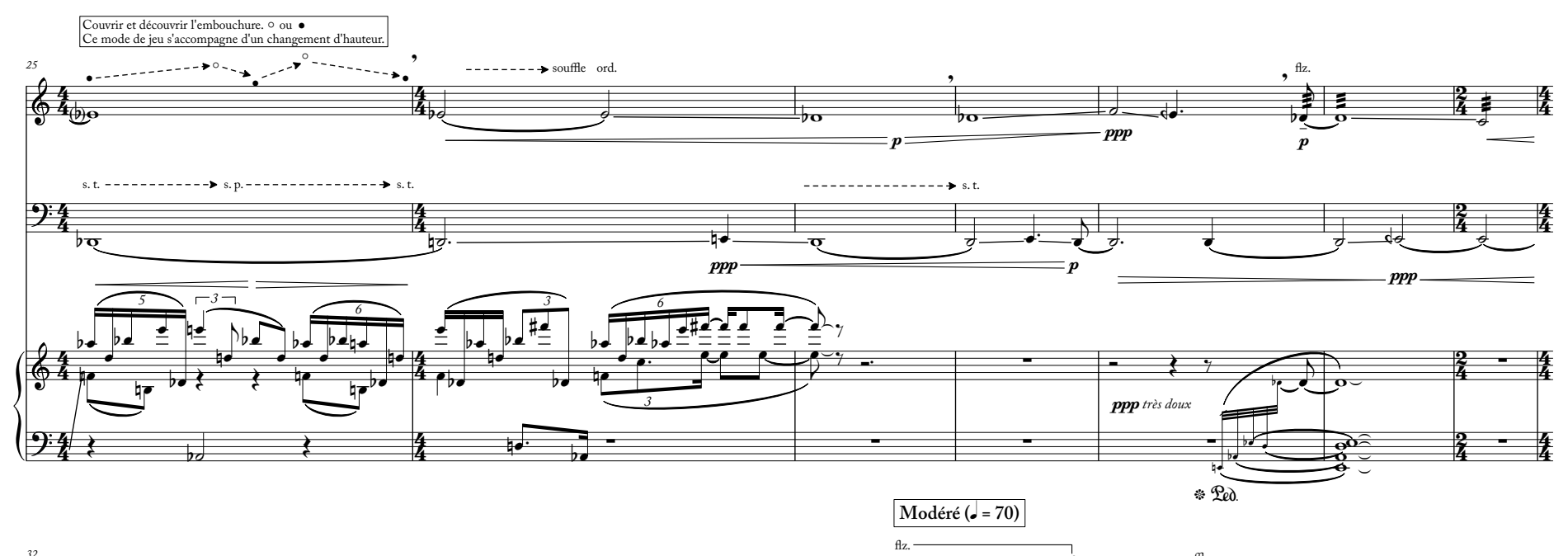

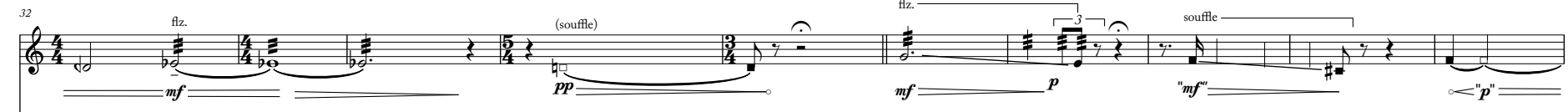

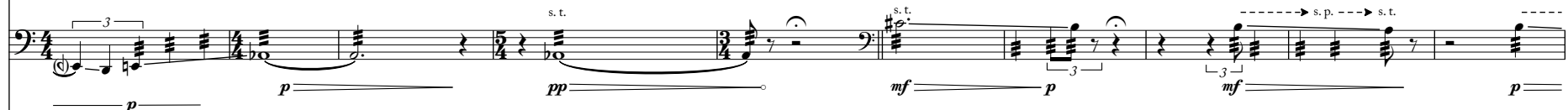

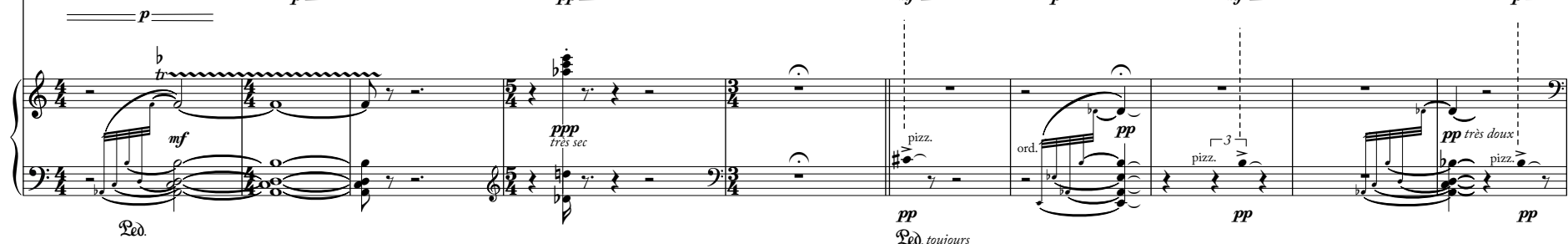

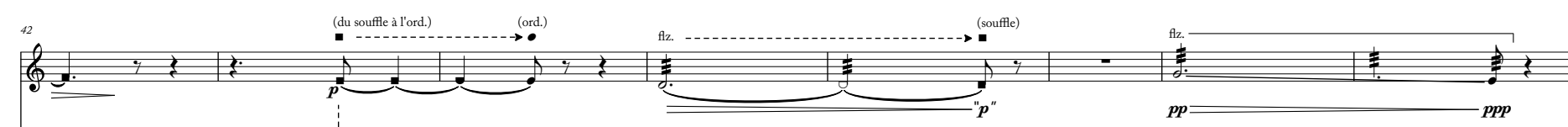

(f) (c) Q acurpidid doit

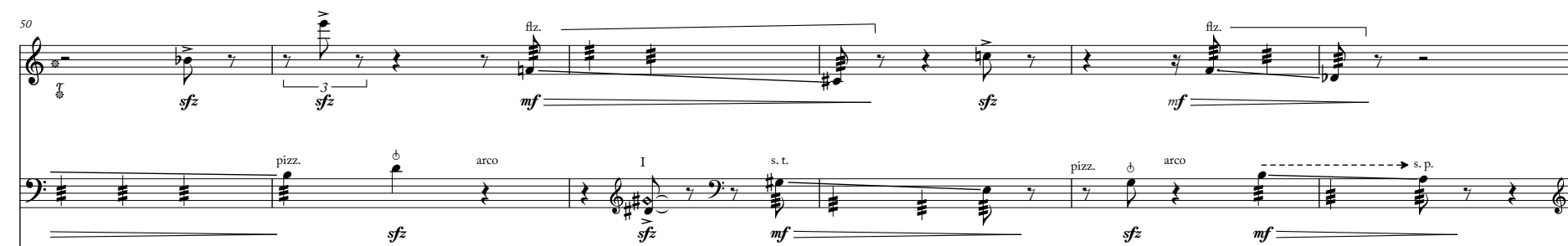

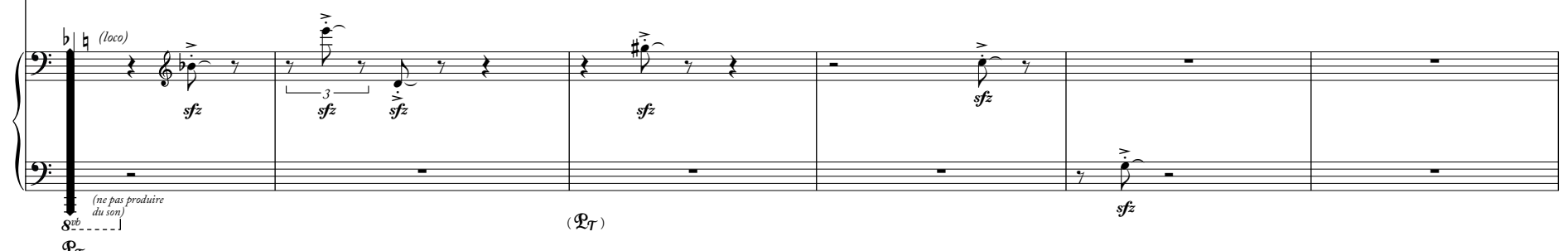

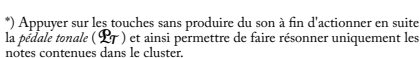




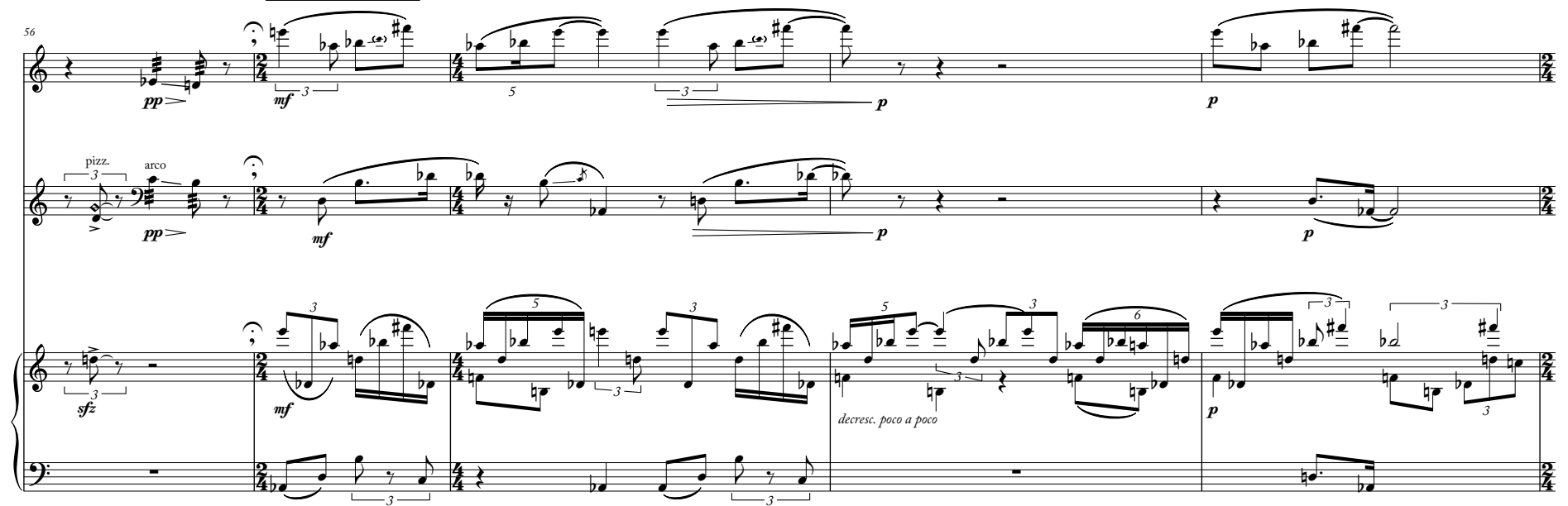

$\left(\mathbb{Q}_{\mathcal{T}}\right)$

* Red ad libitum
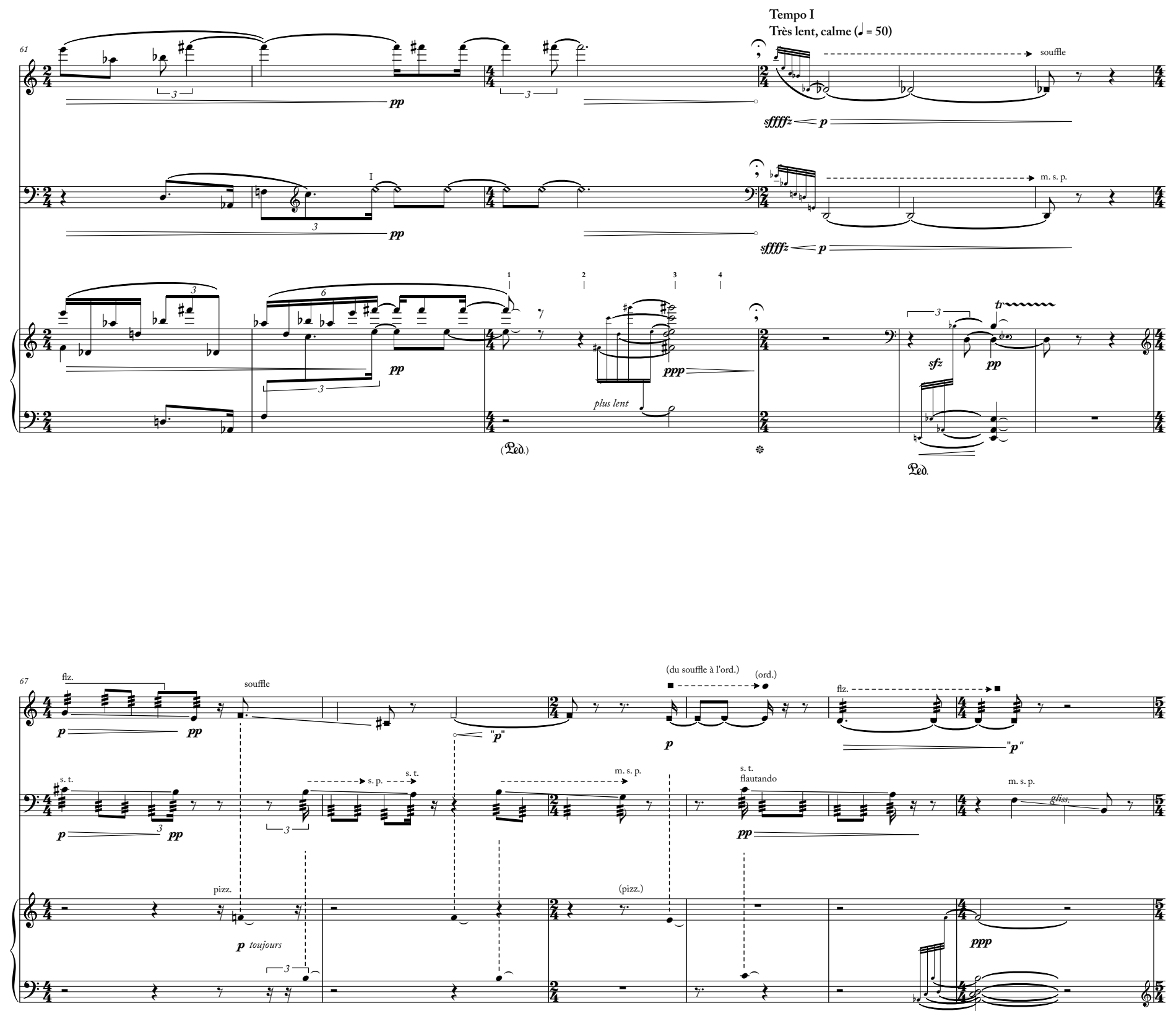

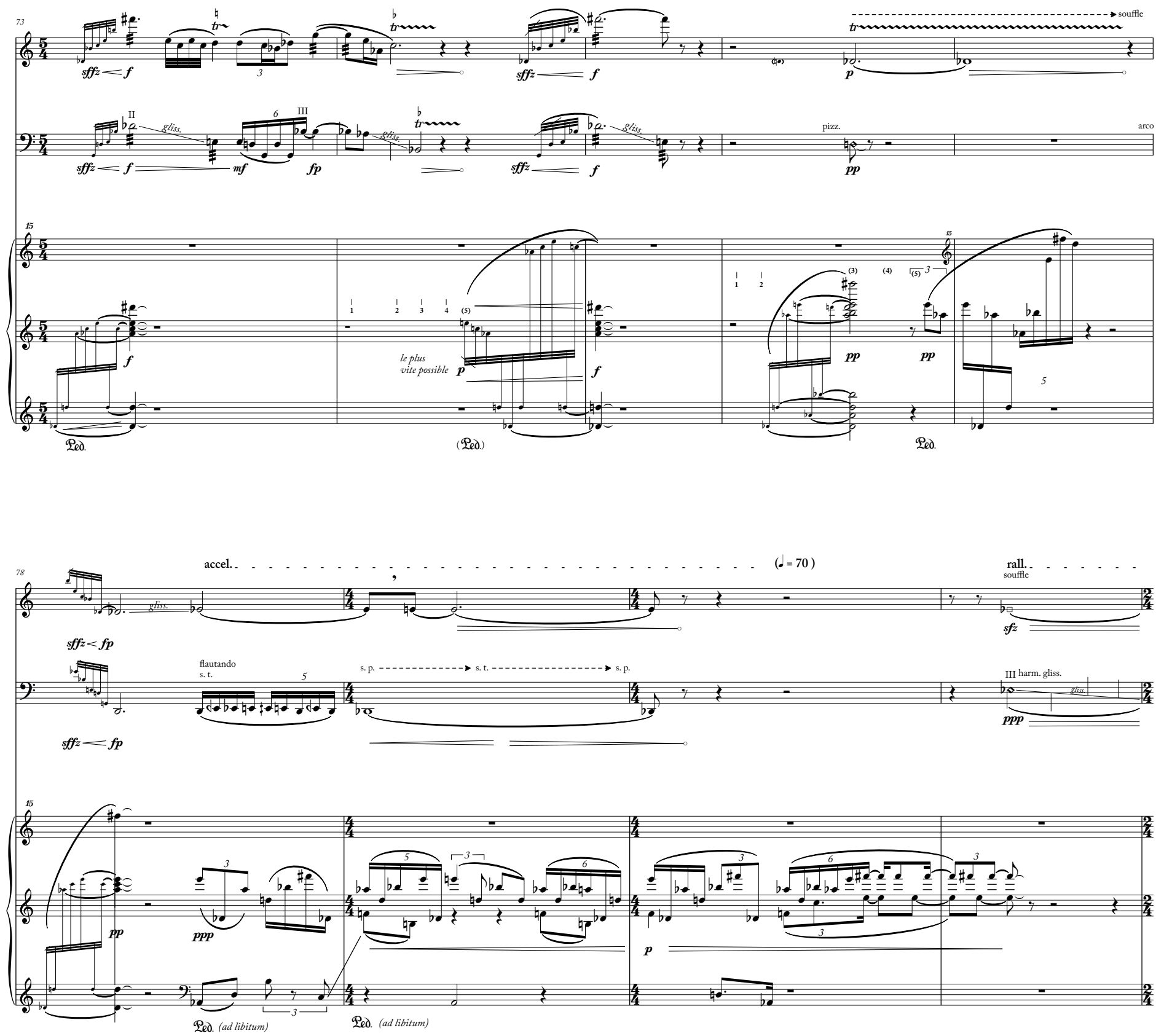

$0=65$

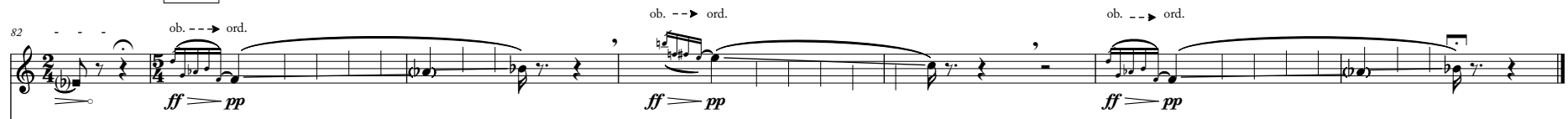
(2)

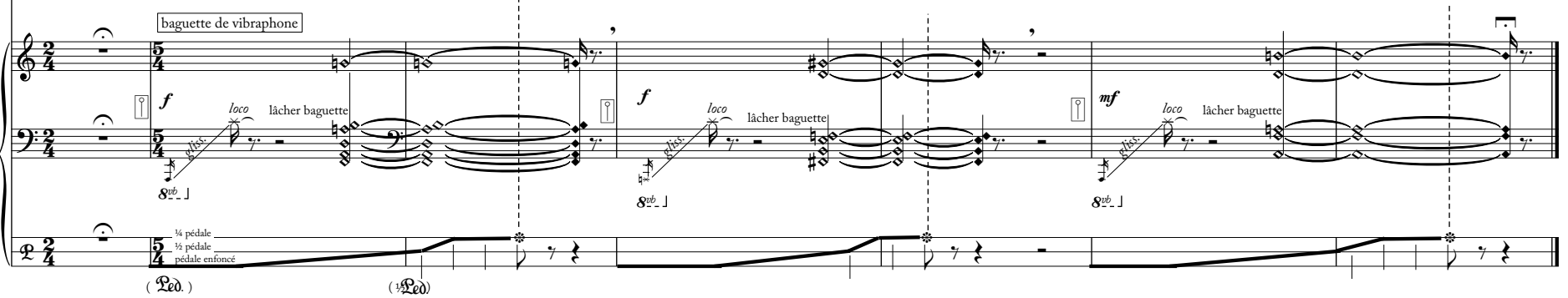

